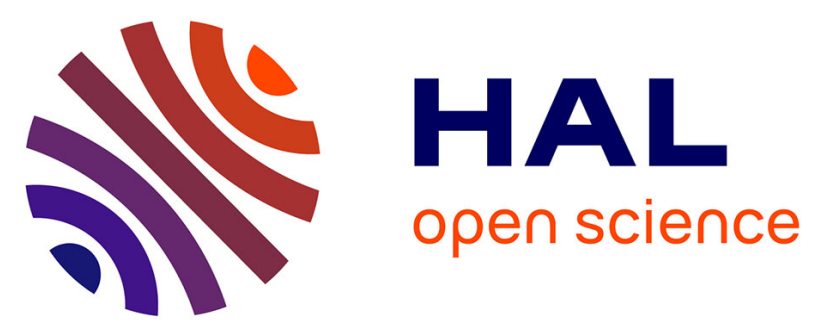

\title{
Development of serological proteome analysis of mastitis by Staphylococcus aureus in ewes.
}

\author{
C. Le Maréchal, Gwénaël Jan, Sergine Even, J. A. Mcculloch, V. Azevedo, \\ Régis Thiery, E. Vautor, Yves Le Loir
}

\section{- To cite this version:}

C. Le Maréchal, Gwénaël Jan, Sergine Even, J. A. Mcculloch, V. Azevedo, et al.. Development of serological proteome analysis of mastitis by Staphylococcus aureus in ewes.. Journal of Microbiological Methods, 2009, 79 (1), pp.131-6. 10.1016/j.mimet.2009.08.017 . hal-00422155

\section{HAL Id: hal-00422155 \\ https://hal-anses.archives-ouvertes.fr/hal-00422155}

Submitted on 6 Oct 2009

HAL is a multi-disciplinary open access archive for the deposit and dissemination of scientific research documents, whether they are published or not. The documents may come from teaching and research institutions in France or abroad, or from public or private research centers.
L'archive ouverte pluridisciplinaire HAL, est destinée au dépôt et à la diffusion de documents scientifiques de niveau recherche, publiés ou non, émanant des établissements d'enseignement et de recherche français ou étrangers, des laboratoires publics ou privés. 
Elsevier Editorial System(tm) for Journal of Microbiological Methods Manuscript Draft

Manuscript Number: MIMET-D-09-00262R1

Title: Development of serological proteome analysis of mastitis by Staphylococcus aureus in ewes.

Article Type: Short Communication

Keywords: Staphylococcus aureus; serological proteome analysis; mastitis; ewe; ruminant; RPMI; 2 dimensional gel electrophoresis

Corresponding Author: Mr Yves Le Loir, Ph.D.

Corresponding Author's Institution:

First Author: Caroline Le Maréchal

Order of Authors: Caroline Le Maréchal; Gwénaël Jan, Ph.D.; Sergine Even, Ph.D.; John A McCulloch, Ph.D.; Vasco Azevedo, Ph.D.; Richard Thiéry, Ph.D.; Eric Vautor, Ph.D.; Yves Le Loir, Ph.D.

Abstract: Staphylococcus aureus is a major agent of mastitis in ruminants worldwide. So far, efficient measures for its prophylaxis (including vaccination) have proven unsuccessful and there is a need for a better understanding of the host response to udder infection by $S$. aureus. Serological proteome analysis (SERPA) is a promising technique that can be used to identify $S$. aureus immunodominant determinants providing that bacterial culture conditions used to grow $S$. aureus strains for protein sample preparation mimic the context of mastitis. A S. aureus strain was used in experimental mastitis to generate sheep serum used to determine the best growth conditions for SERPA. Sera collected in the field from different ewes suffering from mastitis by $S$. aureus were used to confirm experimental observations. Three different culture media (BHI, whey and iron-depleted RPMI) were tested. The influence of aeration and growth phase on protein production was also evaluated by immunodetection of protein samples prepared from cultures grown in different conditions and obtained from different culture fractions (supernatant, cell wall, and total lysates). Our results showed that culturing in iron-depleted RPMI with (secreted proteins, prepared from stationary phase) or without aeration (cell wall proteins, prepared from early stationary phase, and total proteins, prepafed from exponential phase) is the condition that best mimics growth in vivo during mastitis and this in vitro growth condition is to be used henceforth in experiments involving SERPA. 
1 Development of serological proteome analysis of mastitis by Staphylococcus 2 aureus in ewes.

3

4 Le Maréchal, C. ${ }^{1,2,3}$, G. Jan ${ }^{1,2}$, S. Even ${ }^{1,2}$, J.A. McCulloch ${ }^{1,2,4}$, V. Azevedo ${ }^{4}$, R. Thiéry ${ }^{3}$, E. 5 Vautor $^{3 *}$ and Y. Le Loir ${ }^{1,2^{*} \S}$

6

7 \$: Corresponding author, Yves.LeLoir@rennes.inra.fr

$8 \quad$ * $:$ E. Vautor and Y. Le Loir share credit in senior co-authorship in this work

9

10 (1) INRA, UMR1253 STLO, 85 rue de Saint Brieuc, 35042 Rennes Cedex, France.

11 (2) Agrocampus Ouest, UMR1253 STLO, 85 rue de Saint Brieuc, 35042 Rennes Cedex, 12 France

13 (3) Unité de pathologie des ruminants, AFSSA Sophia Antipolis, France

14 (4) Depto de Biologia Geral, ICB / UFMG, Belo Horizonte, Brazil

15

16 Key words: Staphylococcus aureus, serological proteome analysis, mastitis, ewe, ruminant, 17 RPMI 


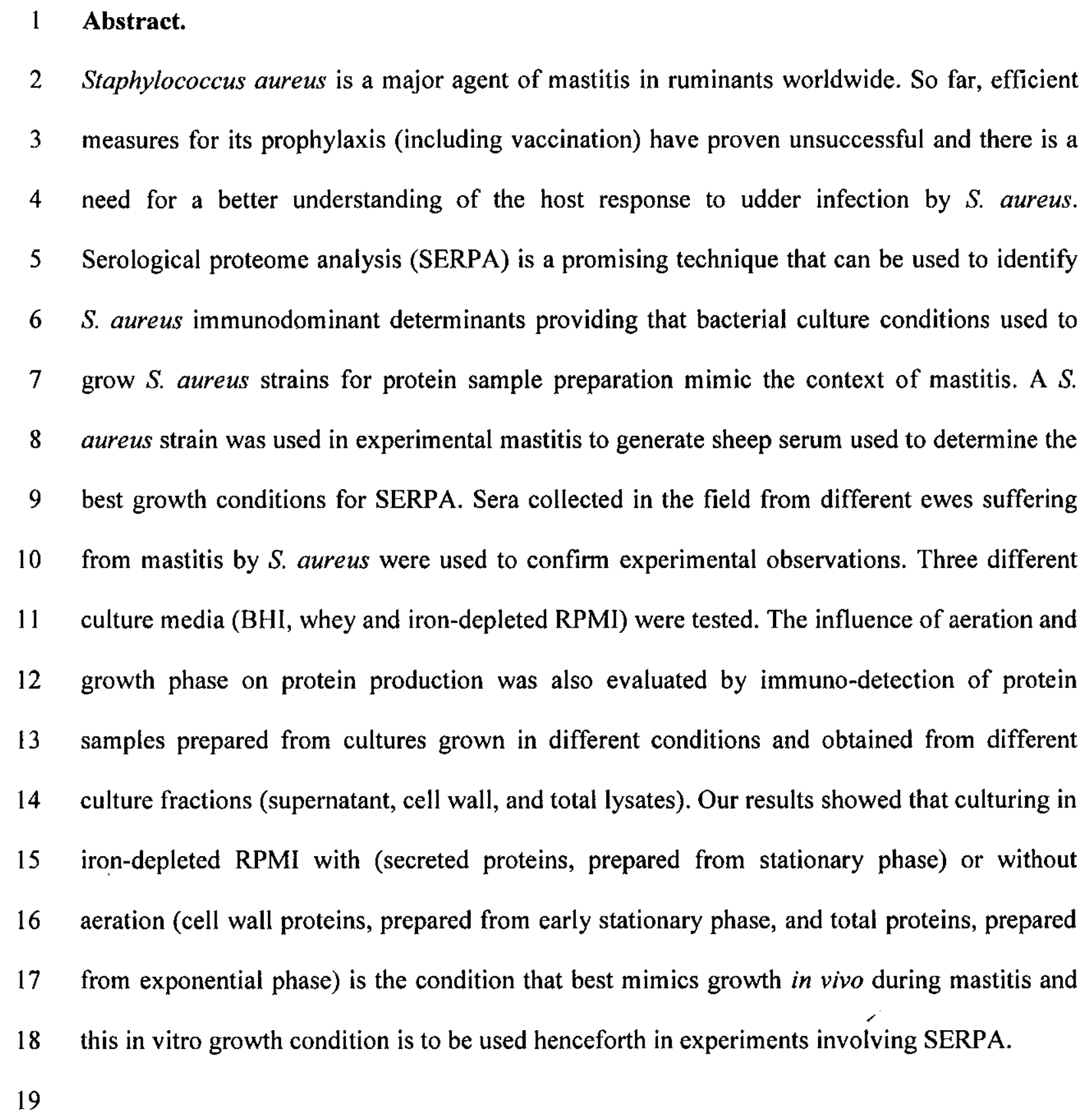

2 Staphylococcus aureus is a major agent of mastitis in ruminants worldwide. So far, efficient 3 measures for its prophylaxis (including vaccination) have proven unsuccessful and there is a 4 need for a better understanding of the host response to udder infection by $S$. aureus. 5 Serological proteome analysis (SERPA) is a promising technique that can be used to identify $6 S$. aureus immunodominant determinants providing that bacterial culture conditions used to 7 grow $S$. aureus strains for protein sample preparation mimic the context of mastitis. A $S$. 8 aureus strain was used in experimental mastitis to generate sheep serum used to determine the 9 best growth conditions for SERPA. Sera collected in the field from different ewes suffering 10 from mastitis by $S$. aureus were used to confirm experimental observations. Three different 11 culture media (BHI, whey and iron-depleted RPMI) were tested. The influence of aeration and 12 growth phase on protein production was also evaluated by immuno-detection of protein 13 samples prepared from cultures grown in different conditions and obtained from different 14 culture fractions (supernatant, cell wall, and total lysates). Our results showed that culturing in 15 iron-depleted RPMI with (secreted proteins, prepared from stationary phase) or without 16 aeration (cell wall proteins, prepared from early stationary phase, and total proteins, prepared 17 from exponential phase) is the condition that best mimics growth in vivo during mastitis and 18 this in vitro growth condition is to be used henceforth in experiments involving SERPA. 19 


\section{Introduction}

2 Staphylococcus aureus is one of the major causative agents of mastitis in ruminants

3 (Bergonier and Berthelot, 2003; Sutra et al., 1990). The impact of $S$. aureus mastitis on milk

4 production is very significant however, the problem is currently hard to tackle for mastitis in

5 dairy cows, sheep and goats. It is typically refractory to antibiotic treatment and prophylactic

6 measures, including the development of an effective vaccine, have so far proven unsuccessful

7 for the control of this disease. Serological proteome analysis (SERPA) is a promising

8 technique that can be used to shed light on the host's immune response to a staphylococcal

9 infection and that was used to mine new antigen candidates for vaccine development in

10 human infections (Vytvytska et al., 2002). SERPA is a combination of 2 dimensional gel

11 electrophoresis (2-DE), immunoblotting and spot sequencing. Proteins extracted from $S$.

12 aureus cultures are separated in 2-DE, transferred onto membranes and exposed to sera from

13 either contaminated or healthy animals. Staphylococcal proteins that are immunogenic are 14 recognized by the serum and can then be determined and characterized. However, protein 15 sample preparation cannot be carried out directly from a sample obtained from a site of 16 infection because the number of bacterial cells present in an infection is too small compared 17 to that required for the preparation of a sample to be submitted to 2D gel electrophoresis. 18 Protein samples therefore have to be prepared from in vitro cultures which leads to the 19 problem that proteins potentially recognized by the serum (which is directed against proteins 20 produced in vivo, during an infection) may not be present when the bacterial strain is cultured 21 in vitro. Indeed, antigen production is different when $S$. aureus is grown in vitro and in vivo 22 (Watson and Prideaux, 1979). It is thus important to find bacterial growth conditions that best 23 mimic mastitis. In this study, experimental mastites were carried out in ewes using a well24 characterized $S$. aureus 046 strain previously isolated from subclinical mastitis in a ewe. The 25 resulting sera were then used to analyze protein samples prepared from $S$. aureus cultures 
1 grown on either whey, Roswell Park Memorial Institute medium (RPMI 1640) depleted of 2 iron or BHI with or without aeration, at different growth phases. Additional sera acquired in 3 the field were used to confirm the results obtained. Growth conditions were compared taking 4 into account the number of proteins detected and the strength of the signals obtained. We 5 hereby determine the in vitro growth conditions that enhance antigen synthesis and can be 6 used for studies of mastitis in ewes using SERPA. 
2 Materials and Methods.

3 Bacterial strains. Staphylococcus aureus strain O46 was previously isolated from a case of

4 ovine subclinical mastitis (Straub et al., 1999; Vautor et al., 2003). The genetic and genotypic

5 background of $S$. aureus $\mathrm{O} 46$ is well-documented and is representative of the major lineage

6 associated with mastitis in ewes in the southeast of France (Vautor et al., 2008).

7 Staphylococcus xylosus, Lactobacillus helveticus, Streptococcus thermophilus, and

8 Escherichia coli strains were used as negative controls for serum analysis. These bacterial

9 species were grown overnight in $\mathrm{BHI}$ broth (Scharlau, Barcelona, Spain) at $37^{\circ} \mathrm{C}$ with 10 agitation, MRS (Difco, Paris, France) at $30^{\circ} \mathrm{C}$ without agitation, M17 (Oxoid, Dardilly, 11 France) at $30^{\circ} \mathrm{C}$ without agitation and LB (Invitrogen, Cergy Pontoise, France) at $37^{\circ} \mathrm{C}$ with 12 agitation for S. xylosus, L. helveticus, S. thermophilus and E. coli, respectively.

14 Preparation of whey. The ewe milk used in this study was obtained from bulk milk, 15 collected at the very beginning of the lactation period of a dairy herd (ewe race Lacaune) in an 16 organic farm close to Rennes (Brittany, France). Ewe milk was microfiltered to remove 17 caseins so as to obtain "ideal whey" corresponding to the microfiltered permeate (MF). 18 Briefly, $50 \mathrm{~L}$ of ewe milk (Triballat, France) were skimmed, heated to $50^{\circ} \mathrm{C}$ and microfiltered 19 using a microfiltration pilot device equipped with a Pall Membralox 1P1940 membrane 20 having a $0.1 \mu \mathrm{m}$ pore size cut-off. Ultrafiltered permeate (UF), where all protein compounds 21 are eliminated, was used to study secreted proteins and was prepared as described previously 22 (Ulve et al., 2008). The same batch of microfiltered and ultrafiltered milk was used 23 throughout this study. 
1 Growth conditions. Strain O46 was cultured separately in three different media: BHI broth

2 (Scharlau), iron-depleted RPMI (Sigma, Saint Quentin fallavier, France) and microfiltered (or

3 ultrafiltered) milk. RPMI 1640 medium was depleted of iron (and hereafter referred to as iron-

4 depleted RPMI) by adding deferoxamine $(0.15 \mathrm{mM})$ (Sigma). All cultures were performed as

5 follows: Overnight cultures in BHI were diluted 1:1000 in fresh medium. For aerobic

6 conditions, $S$. aureus $\mathrm{O} 46$ was grown in $500 \mathrm{~mL}$ flasks under agitation $(150 \mathrm{rpm})$ at $37^{\circ} \mathrm{C}$ (a

7 flask-to-broth volumetric ratio of 5). For anaerobic conditions, S. aureus $\mathrm{O} 46$ was grown in

8 falcon tubes $(50 \mathrm{ml})$ completely filled with medium and incubated at $37^{\circ} \mathrm{C}$ without agitation.

9 Bacteria were either grown to early exponential phase, to early stationary phase or to late 10 stationary phase as determined by measurement of optical density at $600 \mathrm{~nm}\left(\mathrm{OD}_{600}\right)$ and 11 plate counts on BHI agar using a previously described micromethod (Baron et al., 2006).

13 Ewe infection. Experimental mastitis was performed according to the French and European 14 laws on animal experimentations. S. aureus $\mathrm{O} 46$ strain was injected into both teats of a 15 primary lactating ewe 15 days after parturition. Briefly, urethral catheters (Portex ${ }^{\circledR}$ Jackson 16 Cat Catheter, Coveto, France) were inserted into the teat canal after a thorough disinfection of 17 the teat orifice with $70 \%$ ethanol. One millilitre of PBS containing 100 colony-forming-units 18 of $S$. aureus was injected through the catheter, and the catheter removed. Sera were prepared 19 from blood samples collected at D0, D7, D14 and D21 after injection. Briefly, blood samples 20 were stored during at least 2 hours before centrifugation $(2600 \mathrm{rpm}, 15 \mathrm{~min})$. Sera were then 21 carefully taken and stored at $-20^{\circ} \mathrm{C}$.

22 Besides, sera obtained in the field from ewes suffering from S. aureus mastitis were collected 23 at various days after infection (not determined) and prepared similarly. 
1 Sample preparation for SDS-PAGE. Total cell lysates and cell wall proteins were prepared

2 by treatment with lysostaphin as described by Vytvytska et al. with minor changes (Vytvytska

3 et al., 2002). After measurement of $\mathrm{OD}_{600}, 10^{9}$ bacteria were harvested and spun down (5000

$4 \mathrm{x} \mathrm{g}, 5 \mathrm{~min}, 4^{\circ} \mathrm{C}$ ). The volume of culture medium was adjusted according to the type of

5 medium and growth phase to harvest $10^{9}$ bacteria. Cell pellet was washed twice with ice-cold

6 PBS and once with digestion buffer (10 mM Tris- $\mathrm{HCl}$, pH 7.6, $1 \mathrm{mM}$ EDTA, $5 \mathrm{mM} \mathrm{MgCl}$ ).

7 In order to obtain total cell lysates, cells (about $10^{9} \mathrm{cfu}$ ) were resuspended in $1 \mathrm{~mL}$ of

8 digestion buffer containing $1 \mathrm{mM}$ PMSF, $10 \mu \mathrm{L}$ of protease inhibitor cocktail (GE Healthcare,

9 Orsay, France) and $50 \mu \mathrm{g}$ of lysostaphin (Sigma). After incubation at $37^{\circ} \mathrm{C}$ for 30 minutes, 10 cells were exposed to sonication $(5 \times 1 \mathrm{~min})$ and centrifuged at $10000 \times \mathrm{g}$ during 10 minutes 11 at $4^{\circ} \mathrm{C}$. The supernatant was stored at $-20^{\circ} \mathrm{C}$. In order to obtain surface proteins, after 12 washing, cells were resuspended in $1 \mathrm{~mL}$ digestion buffer containing $35 \%$ raffinose (Sigma), $131 \mathrm{mM}$ PMSF (Sigma), $10 \mu \mathrm{l}$ of protease inhibitor cocktail (GE Healthcare) and $100 \mu \mathrm{g}$ of 14 lysostaphin (Sigma). After incubation at $37^{\circ} \mathrm{C}$ during 30 minutes, surface proteins and 15 protoplasts were separated by low speed centrifugation $(2500 \mathrm{x} \mathrm{g}$ during 10 minutes). The 16 supernatant was stored at $-20^{\circ} \mathrm{C}$. Protein concentration was determined using the Bradford 17 reagent in a 96 well plate assay at $595 \mathrm{~nm}$ according to the manufacturer's instructions 18 (Sigma). Cell wall samples were precipitated with 2D clean up kit (GE Healthcare) before 19 electrophoresis. $4 \mu \mathrm{g}$ of proteins from each sample were separated by 1-D electrophoresis. 20 Secreted proteins were prepared according to Ziebandt et al. with minor changes (Ziebandt et 21 al., 2001). The culture was centrifuged at $7000 \mathrm{x}$ g for 10 minutes and the supernatant was 22 filtered through a $0.45 \mu \mathrm{m}$ filter. The secreted proteins were precipitated with $10 \% \mathrm{TCA}$ at $2344^{\circ} \mathrm{C}$ overnight. Protein samples were centrifuged at $7000 \mathrm{x}$ g during 1.5 hours at $4^{\circ} \mathrm{C}$. Protein 24 pellets were washed three times with ethanol $96 \%$, air-dried during 30 minutes and were 25 resuspended in $150 \mu \mathrm{L}$ of sample buffer $(62.5 \mathrm{mM}$ Tris- $\mathrm{HCl}, \mathrm{pH} 6.8 ; 2 \%$ SDS, $5 \%$ DTT, $10 \%$ 
1 glycerol and bromophenol blue). An aliquot of $5 \mu \mathrm{L}$ of the suspension was submitted to 1-D 2 electrophoresis.

3

4 SDS-PAGE and western blotting. Protein extracts were separated by SDS-PAGE on 12\% 5 acrylamide separating slab gels $(70 \times 100 \times 0.5 \mathrm{~mm})$, with a $4 \%$ acrylamide stacking gel on a 6 miniprotean III gel system (BioRad, Ivry sur Seine, France) according to the conditions 7 described by Laemmli (Laemmli, 1970). Migration was performed for $2 \mathrm{~h}$ at room 8 temperature using $80 \mathrm{~V}$ which were kept constant. Samples were diluted in $15 \mu \mathrm{L}$ of sample 9 buffer and denatured at $100^{\circ} \mathrm{C}$ for $3 \mathrm{~min}$. Gels were either stained with Coomassie blue R10250 or transferred onto a PVDF membrane (GE Healthcare) by $250 \mathrm{~mA}$ at $30 \mathrm{~V}$ in Towbin 11 transfer buffer (Towbin et al., 1979) using a Trans-Blot cell (Biorad) for 1.25 hours. 12 Membranes were washed 3 times with Tris Buffered Saline (TBS) pH 7.5 and saturated in 13 blocking solution ( $3 \%$ non-fat dry milk in TBS with Tween $200.3 \%$ (TBS-T)) at $4^{\circ} \mathrm{C}$ 14 overnight. Membranes were then washed $3 \times 10$ minutes with TBS-T and incubated with 15 serum (1:40 000 in $25 \mathrm{~mL}$ of blocking solution) for 1 hour at room temperature. After 16 washing, membranes were incubated with alkaline phosphatase-conjugated anti-sheep $\lg$ G 17 (Sigma) diluted 1:15 000 in $25 \mathrm{ml}$ blocking solution for one hour and finally BCIP/NBT 18 (Sigma) was used to visualize reactive proteins, according to the manufacturer's instructions.

19 Field sera were compared with the mini-protean II Multiscreen apparatus (Biorad). Briefly, 20 after saturation in blocking solution, the membrane was exposed to the different ewe sera (600 $21 \mu \mathrm{L}$ of serum diluted 1:40 000 in blocking solution) for 1 hour at room temperature. The 22 following steps were similar to the ones described above. 
1 Image analysis. Immuno-developed Western blots were scanned using an Image Scanner II 1

2 (Amersham biosciences) and further analyzed using ImageQuant 1D software. The number, 3 volume and area of bands were taken into account for the analysis. 


\section{Results and discussion}

2

3 Choice of culture media and $S$. aureus growth conditions. Three different culture media

4 were tested in this study. Brain Heart Infusion broth (BHI), which is a rich, non-selective and

5 non-buffered culture medium commonly used for growing $S$. aureus and other bacteria. BHI

6 was used as a control medium in this study.

7 The Roswell Park Memorial Institute medium (RPMI), a synthetic medium for eukaryotic cell

8 culture, which had already been used for culturing $S$. aureus for use in proteomic experiments.

9 Notably, it has been shown that iron depleted RPMI 1640 enhances the production of antigens 10 compared to BHI as determined by SERPA analysis using human sera (Vytvytska et al., 11 2002). Growth conditions in which there is restriction in the bioavailability of iron can lead to 12 an increase of the expression of virulence factors which are normally expressed in vivo 13 (Trivier et al., 1995). The extremely low availability of iron in mammalian interstitial fluid 14 due to the presence of transferrins is an important environmental growth criterion for bacteria.

15 In growth conditions where there is a low concentration of iron and competition for iron with

16 transferrins, $S$. aureus derepresses the genes encoding siderophores, which are low-molecular-

17 mass iron chelators and specific cell wall protein receptors (Modun et al., 1992).

18 Milk and whey have been reported to be media that mimic the growth conditions faced by 19 Staphylococcus in mastitis (Lammers et al., 2000). Whey was compared to tryptic soy broth 20 (TSB) and was shown to induce the production of in vivo-like antigens (Mamo and Froman, 21 1994b), adhesion of $S$. aureus to bovine mammary epithelial cells (Mamo and Froman, 22 1994a), anti-phagocytic surface properties (Mamo et al., 1991b) and to enhance virulence of 23 S. aureus (Mamo et al., 1991a) whereas TSB did not. UF instead of MF was used to study 24 secreted proteins because the presence of milk proteins in MF dramatically impairs secreted 25 protein precipitation. 
1 Both RPMI and whey media seem to mimic in vivo conditions, however, they have never

2 been compared to each other as culture media to determine which one best mimics the 3 mastitis-like growth conditions.

$4 S$. aureus $\mathrm{O} 46$ was cultivated on each of the three media, with and without agitation (Figure

5 1). Both ewe whey and BHI sustained rapid growth of the strain whereas growth on iron6 depleted RPMI was significantly slower in both aerobic and anaerobic growth conditions. The 7 calculated growth rates were $0.75 \mathrm{~h}^{-1}, 0.85 \mathrm{~h}^{-1}$ and $0.62 \mathrm{~h}^{-1}$, for cultivation with agitation on 8 ewe whey, BHI and iron-depleted RPMI, respectively. They were slightly lower $\left(0.58 \mathrm{~h}^{-1}\right.$, $90.68 \mathrm{~h}^{-1}$ and $0.59 \mathrm{~h}^{-1}$ ), for cultivation without agitation. In spite of this, final biomasses did not 10 vary significantly from one medium to another. The time points for culture sample collection 11 in the exponential and stationary phases of growth were determined according to these growth 12 conditions (Figure 1).

13 14 15 16 17 18 19 52 
1 2002). The considerably large dilution required for immune-revelation with the sera was due

1

2 to the presence of a wide range of antistaphylococcal antibodies found even in healthy

3 animals (i.e. animals which never suffered from mastitis; (Dryla et al., 2005; Tedeschi et al.,

4 2008). This observation is corroborated in our Western blot experiments: sera from

5 primiparous ewes without mastitis or even from new born lambs recognized some

6 staphylococcal antigens (Figure 4; lanes 7-10).

7 The specificity of the serum obtained was tested against protein samples (total lysates)

8 prepared from $S$. aureus, Staphylococcus xylosus, Lactobacillus helveticus, Streptococcus

9 thermophilus and Escherichia coli cultures (Figure 2). A dilution of 1/40,000 of the serum 10 obtained at D14 was used to reveal the protein samples. Only 6 proteins were revealed in the $11 S$. xylosus extract. Two of these proteins co-migrated with $S$. aureus proteins. Such cross12 hybridizations may be due to the similarity of some proteins found in the Staphylococcus 13 genus. However, the signals generated by these cross-hybridizations were faint. Similarly, 14 faint signals were also obtained with $E$. coli samples (Figure 2). Besides, one cannot exclude 15 that those faint signals were due to previous infections by a staphylococcal and or an E. coli 16 strain.

18 Impact of culture medium, growth phase and aeration on immunogenic protein 19 production in S. aureus. $S$. aureus protein production is reportedly dependant on i) medium 20 composition (Trivier and Courcol, 1996; Watson and Prideaux, 1979), ii) growth phase of the 21 S. aureus culture (Novick, 2003) and iii) oxygen availability (Mayer et al., 1988; Ster et al., 22 2005). Combinations of these three parameters were tested using protein samples prepared 23 from bacteria harvested at various culture growth phases, and grown in various culture 24 conditions and media. The most relevant results obtained are presented in Figure 3. Among 25 the three media tested, iron-depleted RPMI was the medium where $S$. aureus 046 produced 
1 the most numerous immunodetected proteins with up to 22 different immunodetected proteins

2 and the highest average signal volume whatever the growth phase (not shown), culture

3 fractions, or culture conditions analyzed. In the different fractions tested, only a few bands

4 were detected in protein samples prepared from cultures grown on BHI or whey, whereas they

5 were not detected or were much fainter in iron-depleted RPMI samples (Figure 3). Using

6 human sera, Vytvytska et al. demonstrated that cultivation in iron-depleted RPMI induced a

7 greater production of antigenic proteins in $S$. aureus compared to cultivation on BHI. Other

8 works suggested that $S$. aureus cultivation in milk or whey induced the production of in vivo-

9 like antigens compared to growth in laboratory rich media. Our study compared for the first

10 time three culture media and showed that, unexpectedly, iron-depleted RPMI better mimics

11 mastitis conditions than do the other two media tested.

13 the expression of virulence factors is tightly regulated by the accessory gene regulator (agr), a 14 central system in virulence regulation based on quorum sensing (Mayer et al., 1988; Novick, 15 2003). In order to determine which growth phase corresponded to the most abundant antigen 16 production, total cell lysate and cell wall protein samples were prepared from cells harvested 17 at different time intervals corresponding to exponential phase, early stationary phase, and late 18 stationary phase. Signals obtained with total cell lysate were more numerous and stronger 19 when protein samples were prepared from exponential compared to early- or late- stationary 20 phase. Cell wall proteins samples prepared from early stationary phase generated more 21 numerous and stronger signals compared to those prepared from log or late stationary phase 22 (not shown). Conversely, the number and strength of western blot signals from secreted 23 proteins (culture supernatant samples) increased from early exponential phase to late 24 stationary phase (not shown). The absence of lactate dehydrogenase activity (a typically 25 intracellular enzyme) in each of the supernatant fractions was demonstrated as shown 
1 previously (Hillier and Jago, 1982). Moreover, protein patterns were dramatically different

3 accumulation was not due to $S$. aureus cell lysis in late stationary phase. Late stationary phase

4 was thus kept for further analysis of supernatant fraction. These observations can be

5 corroborated with the agr-dependant induction of secreted proteins when $S$. aureus culture

6 reaches the post-exponential growth phase (Novick, 2003).

7 Oxygen concentration is an important parameter in $S$. aureus growth and $S$. aureus 8 gene expression varies dramatically between aerobic and anaerobic conditions (Fuchs et al., 9 2007; Ster et al., 2005). During mastitis, the $\mathrm{O}_{2}$ concentration in milk decreases dramatically 10 to a level below $10 \%$ of the one found in normal milk (Mayer et al., 1988). In order to test the 11 effect of oxygen on the in vitro production of immunogenic proteins, S. aureus 046 was 12 grown in whey, BHI and iron-depleted RPMI with or without aeration and protein extraction 13 was carried out during exponential phase and stationary phase. Among the set of conditions 14 tested, cell lysate protein samples prepared from the exponential phase of growth in iron 15 depleted RPMI without agitation resulted in the highest number of immunodetected proteins 16 (19) compared with the other conditions (from 8 in BHI without agitation to 18 in MF without 17 agitation). Band intensity and band area means were higher in samples prepared from iron18 depleted RPMI without aeration (Figure 3A). Of note, intensity (or volume) and area of the 19 bands were slightly lower in iron depleted RPMI without aeration compared to the same 20 medium with aeration ( 0.95 time lower for intensity and 0.92 for area). However, the number 21 of bands present was much higher without aeration (19 versus 13).

22 For cell wall protein extracts, iron depleted RPMI without aeration resulted in the 23 highest number of immunodetected bands. This showed that protein samples from the 24 stationary phase of growth in iron depleted RPMI without aeration enhanced immunoreactive 25 cell wall protein synthesis (Figure 3B). This result is in contradiction with agr dependant 
1 regulation of surface protein production in $S$. aureus, which is up-regulated during 2 exponential phase and down-regulated during stationary phase. However, agr-dependant 3 regulation mostly controls virulence related genes and, in a mastitis context, immunoreactive 4 proteins are not necessarily virulence factors (Tedeschi et al., 2008).

Regarding the secreted proteins, protein samples prepared from supernatants of

6 stationary phase of the $S$. aureus culture grown in iron depleted RPMI with aeration resulted 7 in the highest number of detected bands (23) with the highest intensity and band area mean 8 (Figure 3C). Iron depleted RPMI with low oxygen yielded an interesting profile but both the 9 number of bands (22) and the signal intensity (1.4 times lower) were lower. These results 10 were in accordance with the temporal regulation of virulence factor expression by the agr 11 system: the expression of genes encoding secreted proteins (e.g. toxins) is activated during the 12 late exponential phase (Novick, 2003). These virulence factors are reportedly highly 13 immunogenic in an infectious context.

14 15
Variations in the pattern of $S$. aureus 046 proteins immuno-detected with various ewe sera obtained in the field. The protein patterns of $S$. aureus strains involved in mastitis may vary from one strain to another. Similarly, the immune response of the ewes may vary from an individual to another during mastitis as well as in healthy carriage. As such, ewe sera obtained in the field collected from cases of mastitis involving uncharacterized $S$. aureus strains are likely to generate a variety of immuno-detected protein patterns. To test this hypothesis, protein samples were prepared from $S$. aureus 046 grown in the culture conditions selected in this work. The protein samples were further used for immuno-detection using 10 different ewe sera (Figure 4). Sera were collected from 5 different ewes suffering from diagnosed $S$. aureus mastitis and from 4 healthy animals. The results obtained showed that healthy animals produced antibodies against $S$. aureus (Figure 4, lanes 7 to 10). This can be correlated to the high prevalence of $S$. aureus healthy carriage in sheep flock (Vautor et al., 
1 2005). Serum from a new born lamb recognized only 2 proteins with a low intensity. The

2 signal intensity generated by the immunodetection using healthy animal sera was low.

3 Overexposition of the immunoblots did not reveal significantly different protein patterns. This

4 suggests that, as opposed to what happens in healthy carriage, the involvement of $S$. aureus in

5 mastitis induces a specific and strong immune response.

6 The majority of ewes with mastitis presented high antibody levels against S. aureus (Figure 4,

7 lane 1 to 6 ). One of the sera collected (lane 4) revealed S. aureus 046 proteins with a very 8 high intensity. Most of the bands present in profile 1 were also present in the other profiles.

9 Some additional bands were detected in lane 4, especially the ones presenting a low molecular 10 weight. These results showed that immunogenic proteins synthesized during growth in iron 11 depleted RPMI are also recognized by field sera. Experimental infection is a useful approach 12 to identify immunogenic proteins that are recognized by ewe antibodies. However, the use of 13 sera obtained in the field can be a useful tool to validate the immunogenic proteins recognized 14 by animals infected by different strains. Such comparisons might help in identifying and 15 defining a $S$. aureus core seroproteome (i.e. the pool of $S$. aureus proteins common to all $S$. 16 aureus strains and recognized by any of the ewe sera tested) and an accessory seroproteome 17 (i.e. the pool of immuno-detected proteins that vary with the $S$. aureus strains and the ewe 18 infected).

20 Conclusion. SERPA is a promising technique that can be used to investigate immuno21 dominant proteins produced by $S$. aureus in a mastitis context, providing that the growth 22 conditions of the $S$. aureus strains used for protein sample preparation mimic as best as 23 possible the environmental conditions of mastitis and induce the expression of the relevant 24 staphylococcal antigens. In this study, we determined that culturing in iron-depleted RPMI is 25 the condition that induces the expression and production of the most numerous and immune- 
1 responsive staphylococcal antigens, and therefore, the condition that best mimics mastitis.

2 The exponential phase is the ideal growth phase to study antigens present in total cell lysate

3 and early stationary phase is the ideal one to study antigens present in cell wall fractions and

4 in both cases low oxygen enhanced more antigen production. Conversely, late stationary 5 phase in presence of oxygen is the best culture condition to study secreted antigens. The

6 limitation of oxygen appears to be an essential parameter for the mimicking of a mastitis 7 condition. Whey was expected to enhance the in vivo expression of antigens but this was not 8 confirmed in this study. However, we used microfiltered whey instead of whey obtained from 9 curd draining after acidification (Mamo et al., 1991a; Mamo et al., 1991b; Mamo and Froman, 10 1994a; Mamo and Froman, 1994b). Variations in whey composition may explain the 11 differences observed here. Growth in whey may induce other kind of non proteinous antigens 12 such as capsular polysaccharides (Sutra et al., 1990) which are also immunogenic (Dryla et 13 al., 2005). The experimental conditions determined in this study are crucial to further develop 14 a SERPA approach for the identification of $S$. aureus antigens involved in the sheep immune 15 response during mastitis.

17 Acknowledgements. Authors are grateful to Pascal Rainard (IASP, INRA Tours, France) for 18 valuable discussion all along this work. Caroline Le Maréchal is the recipíent of a PhD grant 19 from the Institut National de la Recherche Agronomique (INRA) and the Agence Française de 20 Sécurité Sanitaire et Alimentaire (AFSSA), IMISa Project. John McCulloch was the recipient 21 of a CAPES post-doctoral grant from the Brazilian government (CAPES-COFECUB project $22539 / 06)$. 
Baron, F., M. F. Cochet, N. Grosset, M. N. Madec, F. Gonnet, S. Jan, and M. Gautier. 2006. Rapid and cost-effective method for micro-organism enumeration based on miniaturization of the conventional plate-counting technique. Le Lait 86(3):251-257.

Bergonier, D., and X. Berthelot. 2003. New advances in epizootiology and control of ewe mastitis. Livestock. Production. Science 79(1):1-16.

Dryla, A., S. Prustomersky, D. Gelbmann, M. Hanner, E. Bettinger, B. Kocsis, T. Kustos, T. Henics, A. Meinke, and E. Nagy. 2005. Comparison of antibody repertoires against Staphylococcus aureus in healthy individuals and in acutely infected patients. Clin. Diagn. Lab Immunol. 12(3):387-398.

Fuchs, S., J. Pane-Farre, C. Kohler, M. Hecker, and S. Engelmann. 2007. Anaerobic gene expression in Staphylococcus aureus. J. Bacteriol. 189(11):4275-4289.

Hillier, A. J., and G. R. Jago. 1982. L-Lactate dehydrogenase, FDP-activated, from Streptococcus cremoris. Methods Enzymol. 89 Pt D:362-367.

Laemmli, U. K. 1970. Cleavage of structural proteins during the assembly of the head of bacteriophage T4. Nature 227(5259):680-685.

Lammers, A., E. Kruijt, K. C. van de, P. J. Nuijten, and H. E. Smith. 2000. Identification of Staphylococcus aureus genes expressed during growth in milk: a useful model for selection of genes important in bovine mastitis? Microbiology 146 ( Pt 4):981-987.

Mamo, W., and G. Froman. 1994a. Adhesion of Staphylococcus aureus to bovine mammary epithelial cells induced by growth in milk whey. Microbiol. Immunol. 38(4):305-308.

Mamo, W., and G. Froman. 1994b. In vivo-like antigenic surface properties of Staphylococcus aureus from bovine mastitis induced upon growth in milk whey. Microbiol. Immunol. 38(10):801-804.

Mamo, W., M. Lindahl, and P. Jonsson. 1991a. Enhanced virulence of Staphylococcus aureus from bovine mastitis induced by growth in milk whey. Vet. Microbiol. 27(3-4):371384.

Mamo, W., C. H. Sandgren, M. Lindahl, and P. Jonsson. 1991b. Induction of anti-phagocytic surface properties of Staphylococcus aureus from bovine mastitis by growth in milk whey. Zentralbl. Veterinarmed. B 38(6):401-410.

Mayer, S. J., A. E. Waterman, P. M. Keen, N. Craven, and F. J. Bourne. 1988. Oxygen concentration in milk of healthy and mastitic cows and implications of low oxygen tension for the killing of Staphylococcus aureus by bovine neutrophils. J. Dairy Res. 55(4):513-519. 
Modun, B., P. Williams, W. J. Pike, A. Cockayne, J. P. Arbuthnott, R. Finch, and S. P. Denyer. 1992. Cell envelope proteins of Staphylococcus epidermidis grown in vivo in a peritoneal chamber implant. Infect. Immun. 60(6):2551-2553.

Novick, R. P. 2003. Autoinduction and signal transduction in the regulation of staphylococcal virulence. Mol. Microbiol. 48(6):1429-1449.

Ster, C., F. B. Gilbert, T. Cochard, and B. Poutrel. 2005. Transcriptional profiles of regulatory and virulence factors of Staphylococcus aureus of bovine origin: oxygen impact and strain-to-strain variations. Mol. Cell Probes 19(4):227-235.

Straub, J. A., C. Hertel, and W. P. Hammes. 1999. A 23S rDNA-targeted polymerase chain reaction-based system for detection of Staphylococcus aureus in meat starter cultures and dairy products. J. Food Prot. 62(10):1150-1156.

Sutra, L., P. Rainard, and B. Poutrel. 1990. Phagocytosis of mastitis isolates of Staphylococcus aureus and expression of type 5 capsular polysaccharide are influenced by growth in the presence of milk. J. Clin. Microbiol. 28(10):2253-2258.

Tedeschi, G., F. Taverna, A. Negri, R. Piccinini, S. Nonnis, S. Ronchi, and A. Zecconi. 2008. Serological proteome analysis of Staphylococcus aureus isolated from sub-clinical mastitis. Vet. Microbiol.

Towbin, H., T. Staehelin, and J. Gordon. 1979. Electrophoretic transfer of proteins from polyacrylamide gels to nitrocellulose sheets: procedure and some applications. Proc. Natl. Acad. Sci. U. S. A 76(9):4350-4354.

Trivier, D., and R. J. Courcol. 1996. Iron depletion and virulence in Staphylococcus aureus. FEMS Microbiol. Lett. 141(2-3):117-127.

Trivier, D., M. Davril, N. Houdret, and R. J. Courcol. 1995. Influence of iron depletion on growth kinetics, siderophore production, and protein expression of Staphylococcus aureus. FEMS Microbiol. Lett. 127(3):195-199.

Ulve, V. M., C. Monnet, F. Valence, J. Fauquant, H. Falentin, and S. Lortal. 2008. RNA extraction from cheese for analysis of in situ gene expression of Lactococcus lactis. J. Appl. Microbiol.

Vautor, E., G. Abadie, J. M. Guibert, N. Chevalier, and M. Pepin. 2005. Nasal carriage of Staphylococcus aureus in dairy sheep. Vet. Microbiol. 106(3-4):235-239.

Vautor, E., G. Abadie, J. M. Guibert, C. Huard, and M. Pepin. 2003. Genotyping of Staphylococcus aureus isolated from various sites on farms with dairy sheep using pulsed-field gel electrophoresis. Vet. Microbiol. 96(1):69-79.

Vautor, E., V. Magnone, G. Rios, B. K. Le, D. Bergonier, G. Lina, H. Meugnier, P. Barbry, R. Thiery, and M. Pepin. 2008. Genetic differences among Staphylococcus aureus isolates from dairy ruminant species: A single-dye DNA microarray approach. Vet. Microbiol. 
Vytvytska, O., E. Nagy, M. Bluggel, H. E. Meyer, R. Kurzbauer, L. A. Huber, and C. S.

Klade. 2002. Identification of vaccine candidate antigens of Staphylococcus aureus by serological proteome analysis. Proteomics. 2(5):580-590.

Watson, D. L., and J. A. Prideaux. 1979. Comparisons of Staphylococcus aureus grown in vitro or in vivo. Microbiol. Immunol. 23(6):543-547.

Ziebandt, A. K., H. Weber, J. Rudolph, R. Schmid, D. Hoper, S. Engelmann, and M. Hecker. 2001. Extracellular proteins of Staphylococcus aureus and the role of SarA and sigma B. Proteomics. 1(4):480-493. 


\section{Figure Legends}

2 Figure 1. Growth kinetics of $S$. aureus $\mathrm{O} 46$ in $\mathrm{BHI}$ ( $\Delta$, upper panel), MF $(\diamond$, middle panel), 3 and RPMI+iron chelator ( $\mathrm{D}$, lower panel) at $37^{\circ} \mathrm{C}$ with (dotted lines) or without (plain lines)

4 agitation. Data are the average of three independent experiments. Arrows indicate the time 5 points when samples were harvested for proteomic analysis.

7 Figure 2. Western blot analysis of $S$. aureus $\mathrm{O} 46$ total cell lysates after growth in iron 8 depleted RPMI without agitation (1), a strain of Staphylococcus xylosus (2), Lactobacillus 9 helveticus (3), Streptococcus thermophilus (4), E. coli (5) using D14 diluted to 1:40 000 ewe 10 serum. Migration positions of size standards are presented on the right side of the figure.

12 Figure 3. Western blot (left panels) and image analysis (right panels) of total lysates (A), cell 13 wall extracts (B) and secreted proteins (C) of S. aureus O46 using D14 diluted 1:40 000 ewe 14 serum. Bacteria were grown in microfiltered milk (MF or UF), Brain Heart Infusion (BHI), or 15 RPMI depleted of iron (RPMI iron -) either with aeration $(+)$ or without aeration $(-)$ and either 16 to exponential phase (A), to early stationary phase (B), or to stationary phase (C). Left panels: 17 Migration positions of size standards and bands detected by image analysis are presented on 18 the left and right side of Western blots, respectively. Right panels: histograms present the number of bands (dashed), band volume (white), and band area (grey) means. Volume and area are expressed in arbitrary units given by the Image Quant 1D software.

Figure 4. Western blot analysis of total lysate proteins of $S$. aureus $\mathrm{O} 46$ grown in iron 24 with clinical mastitis (2), multiparious ewe serum with subclinical mastitis (3), multiparious 25 ewe with subclinical mastitis (4), primiparious ewe serum with clinical mastitis (5), 
1 multiparious ewe with clinical mastitis (6), 3 days lamb serum (7), primiparious lactating 2 lacaune ewe with no mastitis (8), new born lamb serum (9), primiparious lactating lacaune 3 ewe with no mastitis (10). All sera were diluted to 1:40 000. Migration positions of size 4 standards and bands detected by image analysis are presented on the left and right side of 5 Western blots, respectively. Number of bands, (dashed) band volume (white) and band area 6 (grey) means are presented on the graph. Volume and area are expressed in arbitrary units 7 given by the Image Quant 1D software. 
Figure(s)
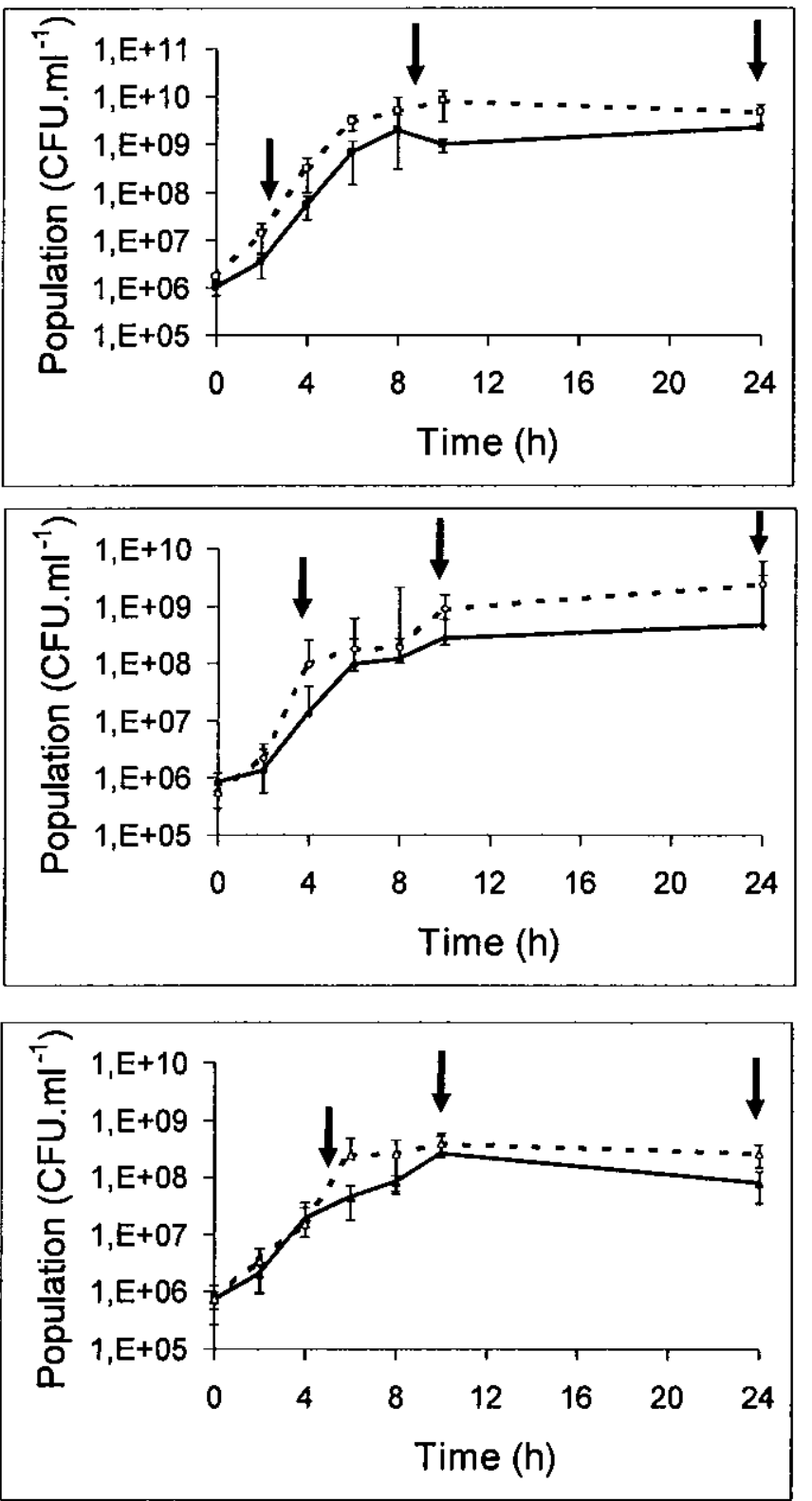

Figure 1 


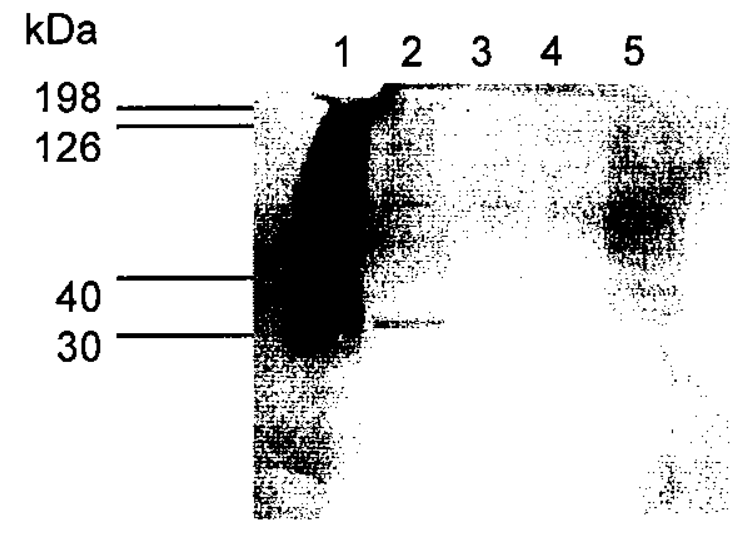

Figure 2 
A
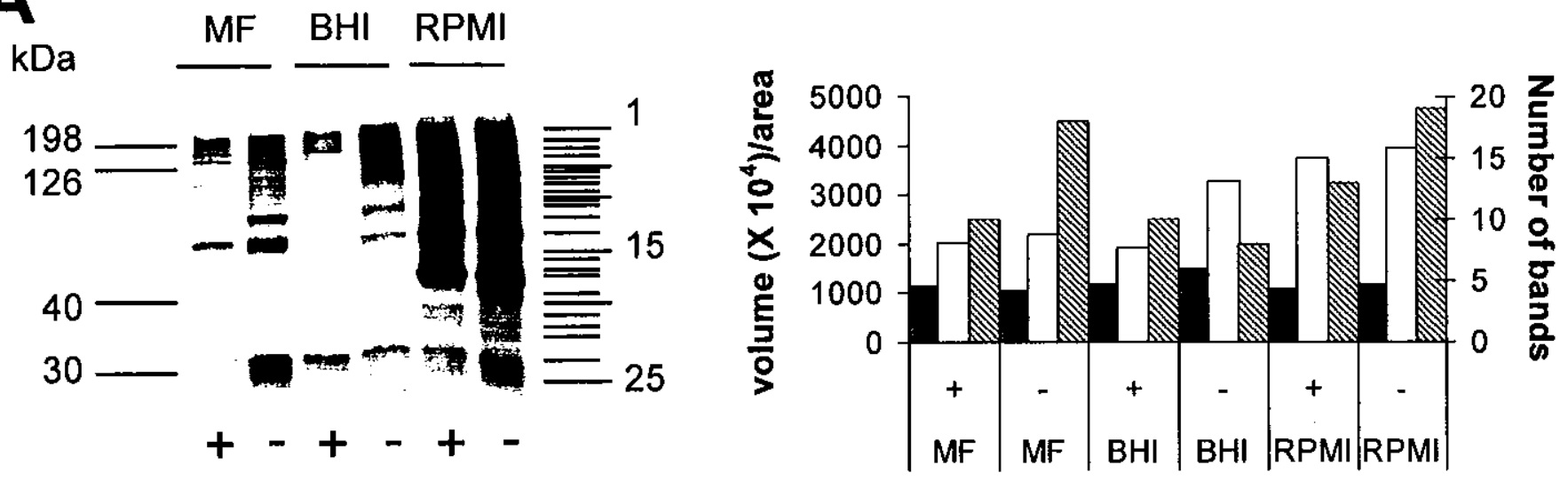

B
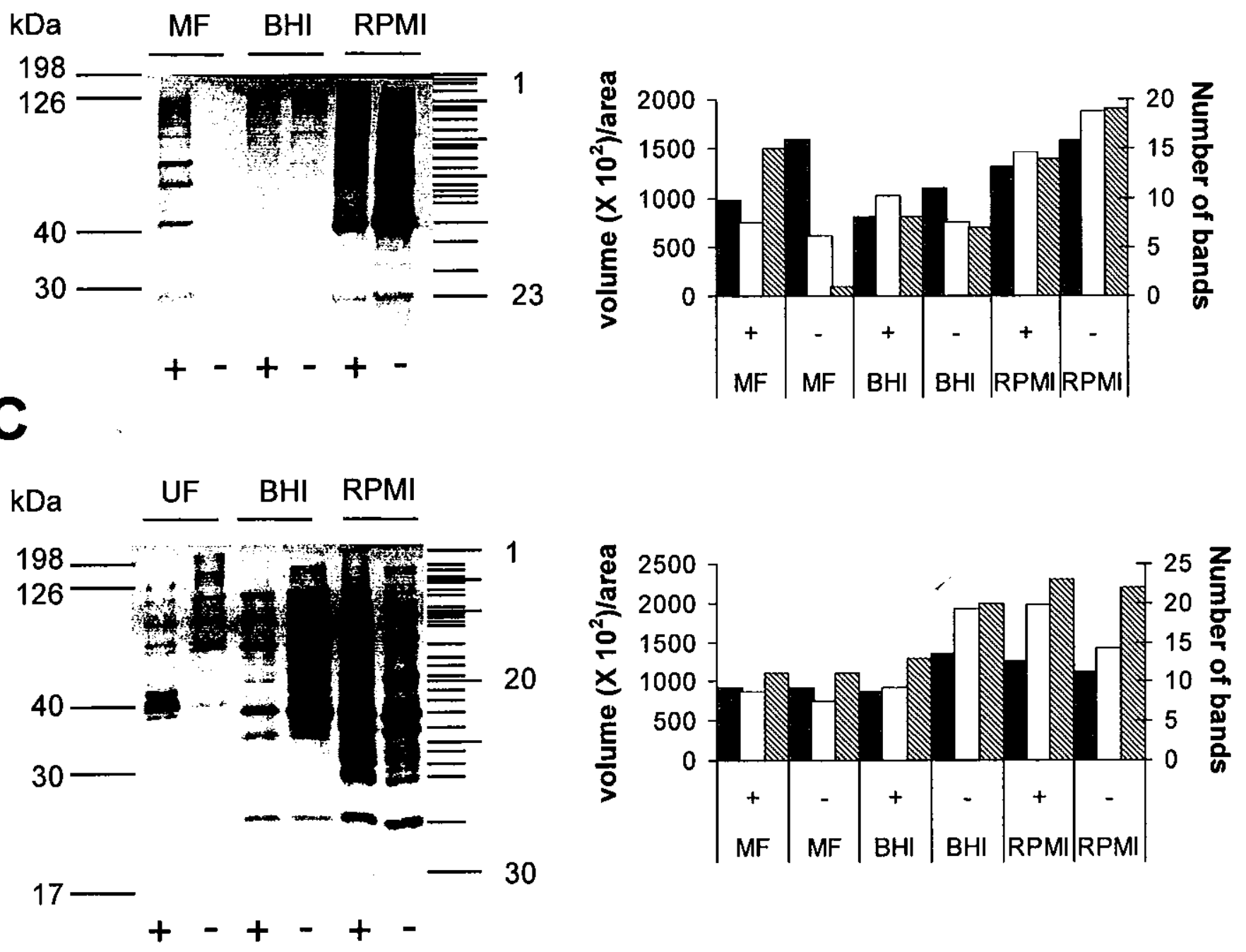

Figure 3 

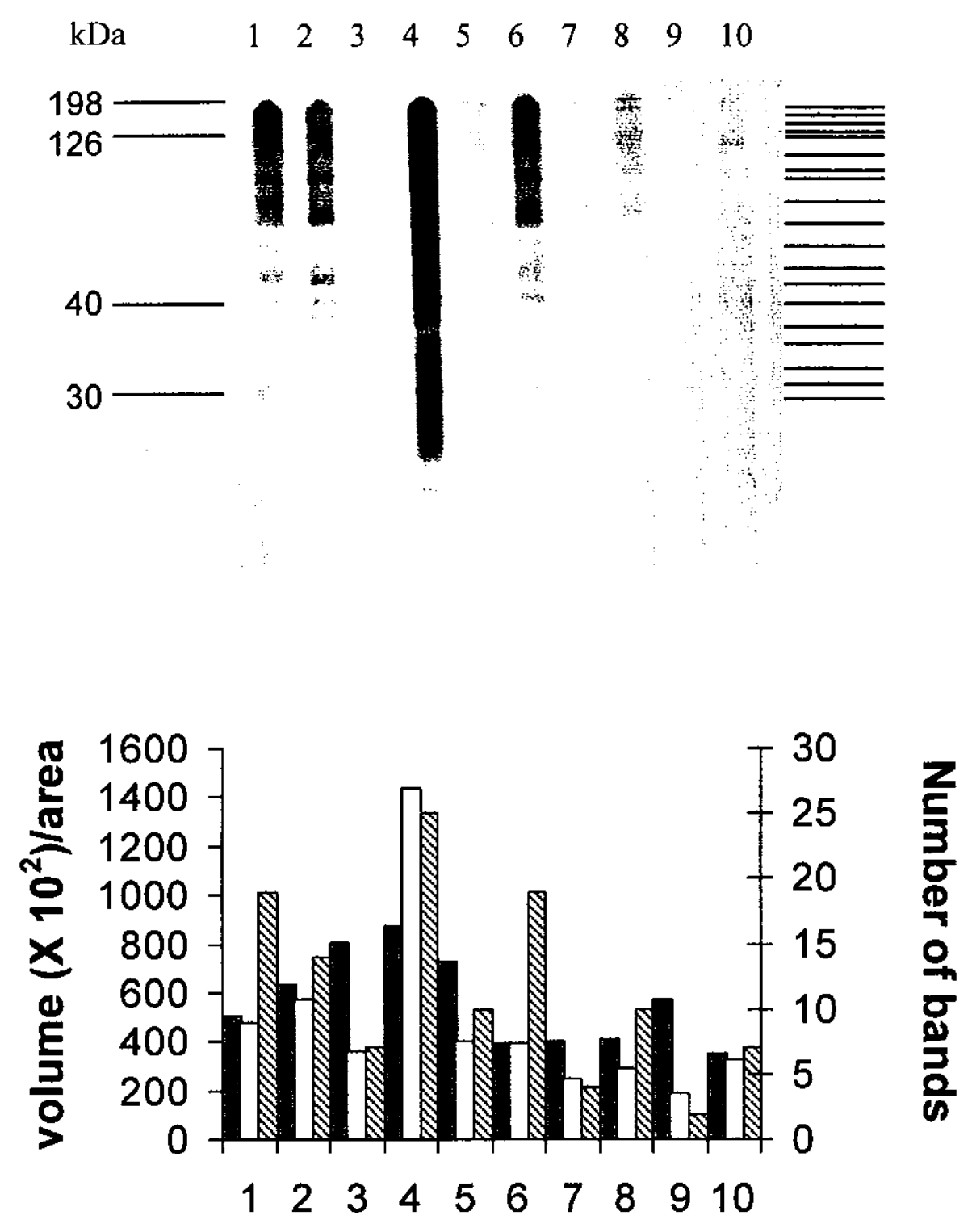

Figure 4 